\title{
Avaliação da Geometria de Ferramenta e Parâmetros do Processo FSW na Soldagem da Liga de Alumínio AA 5052
}

\author{
(Process Parameters and Tool Geometry Evaluation in the FSW of AA 5052 Aluminum Alloy)
}

\author{
Tiago Valdameri Capelari ${ }^{1}$, José Antônio Esmerio Mazzaferro ${ }^{1}$ \\ ${ }^{1}$ Universidade Federal do Rio Grande do Sul - UFRGS, Programa de Pós-Graduação em Engenharia Mecânica - PROMEC, Porto \\ Alegre, RS, Brasil \\ tiago.capelari@ufrgs.br;mazza@ufrgs.br
}

\begin{abstract}
Resumo
A soldagem de ligas de alumínio sem degradação excessiva das propriedades originais do metal base apresenta-se como um obstáculo a ser superado pelas indústrias em seus processos de fabricação, uma vez que o alumínio tem sido usado cada vez de forma mais intensiva. Neste sentido, o processo de soldagem denominado Friction Stir Welding (FSW) tem recebido atenção por suas potencialidades onde o aporte de calor deve ser minimizado ou quando metais dissimilares devem ser soldados. Neste processo, uma ferramenta de alta resistência mecânica e com um perfil especial é utilizada para, por meio de atrito com as peças a serem soldadas, gerar calor e misturar mecanicamente o material da junta, consolidando a solda. Este trabalho visa implementar o processo FSW utilizando uma fresadora universal de elevada rigidez na soldagem de chapas de alumínio AA 5052-H34 com 6,35mm de espessura. Para tanto, três geometrias de ferramentas de soldagem foram projetadas, fabricadas e testadas, de forma a definir-se parâmetros de soldagem compatíveis com as condições fornecidas pela máquina fresadora, por meio de testes preliminares. Definidos estes parâmetros, juntas foram obtidas com as três geometrias de ferramenta disponíveis e seus desempenhos foram comparados. Ensaios mecânicos de dobramento e tração, medição do perfil de microdurezas e análise macrográfica da seção transversal das soldas foram os métodos empregados na caracterização das propriedades resultantes. Em adição, soldas pelo processo MIG também foram obtidas e sujeitas às mesmas avaliações. Considerandose a tensão de escoamento como parâmetro de comparação, as três geometrias testadas apresentaram desempenho similar (em torno de $80 \%$ da tensão de escoamento do metal base). Porém, se comparadas com respeito aos valores de ductilidade ou aos testes de dobramento transversal, observou-se que uma das geometrias testadas tem desempenho inferior às demais devido a presença de uma descontinuidade longitudinal no cordão de solda. O perfil de microdureza das amostras soldadas pelo processo FSW demonstrou homogeneidade entre as diferentes zonas microestruturais existentes ao longo da seção transversal, ao passo que as amostras soldadas através do processo MIG apresentaram variação característica dos processos ao arco elétrico.
\end{abstract}

Palavras-chave: Soldagem; Alumínio; MIG; Friction Stir Welding; Geometria de ferramenta.

\begin{abstract}
Welding of aluminum alloys with no considerable degradation of the properties of the base metal is a problem to be overcomed by industry manufacturing processes. In the aeronautical industry, no-melt joining processes such as adhesive bonding or riveting are often considered when designing aluminum connections. Alternatively, a welding process named Friction Stir Welding (FSW) is receiving crescent attention for its potential applications where heat input shall be minimized or when dissimilar metals must be joined. In this process a high strength rotating tool with a special profile is introduced at the interface of the materials to be joined and translated along the joint at controlled speeds. Heat generated softens the material and allows the tool to stir while traveling along the joint. This work aimed to product welds on AA 5052-H34 plates, $6.35 \mathrm{~mm}$ (0,25 inches) thickness, using a conventional milling machine. In order to do that, three tool geometries were designed, manufactured and tested so as to define which welding parameters could generate the best results. Once these parameters were chosen, each tool produced three welds and their performance was evaluated. Transversal bending, tensile tests, micro-hardness measurements along the weld cross-section and macrographical analysis were carried out in order to assess weld properties. In addition, MIG welds were produced and subjected to the same test conditions. Considering yield stress as an efficiency parameter, all the tested tools presented similar results (around $80 \%$ of the base metal yield stress). However one of these tools showed inferior performance when considering elongation or transversal bending test as a comparison parameter due to the presence of a longitudinal groove, as observed in macrographical analysis. FS welded samples have not showed considerable variation along the different microstructure zones in micro-hardness measurements, while MIG welds presented well defined zones as characteristic to electric-arc processes.
\end{abstract}

Key-Words: Welding; Aluminum; MIG; Friction Stir Welding; Tool Geometry.

(Recebido em 05/11/2008; Texto Final em 13/08/2009). 


\section{Introdução}

A utilização do alumínio e de suas ligas tem experimentado um constante crescimento nos diversos setores da indústria de manufatura, devido às características apresentadas por este metal. O baixo peso específico, aliado à alta resistência mecânica de algumas ligas, faz com que o alumínio seja a primeira escolha em termos de material para atender às exigências de determinadas aplicações. Outra questão que merece destaque é a da reciclagem deste metal. Cerca de $90 \%$ do alumínio presente em veículos é recuperado e reciclado, com enormes vantagens ambientais e econômicas [1].

Os processos de soldagem surgem como um ponto crítico do processo de manufatura do alumínio, uma vez que as propriedades de algumas ligas deste metal acabam por se degradar quando submetido à soldagem por processos convencionais, onde fusão do metal base ocorre. Alternativas visando contornar esta dificuldade imposta por processos tradicionalmente utilizados, como Metal Inert Gas (MIG) ou Tungsten Inert Gas (TIG) surgem em processos de soldagem por fricção, onde a união das peças ocorre sem fusão do material base.

Uma técnica de soldagem que vem ganhando espaço na indústria automotiva e aeronáutica é o processo denominado Friction Stir Welding (FSW). Nesta técnica de soldagem uma ferramenta de elevada resistência mecânica e com um perfil especial é utilizada para, mediante atrito com as peças a serem soldadas, gerar calor promovendo a mistura mecânica dos materiais envolvidos, assim consolidando a solda [2].

Embora a técnica tenha merecido destaque, sendo objeto de estudo em diversos centros de pesquisa tecnológica e Universidades do exterior, pouco se tem observado quanto a trabalhos realizados inteiramente no Brasil. Um dos motivos para isto certamente reside na necessidade de um alto investimento para a obtenção dos equipamentos específicos à soldagem FSW.

Neste sentido esse trabalho visa, a partir de uma aproximação experimental, implementar o processo FSW com o auxílio de uma fresadora universal adaptada para a soldagem de chapas de alumínio AA 5052-H34 com 6,35 mm de espessura. O trabalho também contempla o projeto, fabricação e teste de três geometrias de ferramentas de soldagem, buscando definir as melhores combinações de parâmetros disponibilizados pela máquina utilizada.

Como forma de avaliação do desempenho obtido, as soldas são submetidas à caracterização de suas propriedades mecânicas por meio de ensaios de tração e de dobramento transversal de face e de raiz. A medição da microdureza em diversos pontos sobre a seção transversal também é realizada, buscando quantificar a variação na dureza imposta pelo processo ao longo do perfil. Em adição, macrografias destas seções transversais também são analisadas, visando identificar possíveis descontinuidades oriundas do processo. Na tentativa de traçar um comparativo entre o desempenho dos processos FSW e MIG, soldas por meio deste último foram obtidas e sujeitas as mesmas avaliações impostas ao processo FSW.

\section{Materiais e Métodos}

\subsection{Metal Base}

O metal base utilizado nos ensaios de soldagem foi a liga de alumínio AA5052-H34 com 6,35mm de espessura. Esta liga é endurecida por deformação, apresentando maior resistência e menor ductilidade em relação à condição recozida. A caracterização da liga foi realizada através de ensaios mecânicos de tração e medição de microdureza, permitindo assim a comparação posterior do desempenho obtido pelas juntas soldadas. Em todas as medições de microdureza realizadas no trabalho foi utilizada uma carga de $100 \mathrm{gf}$, aplicada durante $30 \mathrm{~s}$.

Os valores médios de propriedades mecânicas obtidos nos ensaios são aqueles tomados como referência no cálculo da eficiência mecânica da junta soldada, definida como a relação entre o valor da propriedade mecânica resultante após a soldagem e o valor observado no metal base. As propriedades mecânicas do metal base são as apresentadas na Tabela 1 .

A soldagem dos corpos de prova através do processo FSW dividiu-se em duas fases: testes preliminares e soldagem de corpos de prova para análise. Os testes preliminares tiveram como objetivo inicial a adaptação ao processo FSW e a definição e ajuste de parâmetros adequados à soldagem, nesta fase foram utilizados corpos de prova com 30 × $200 \mathrm{~mm}$. A soldagem definitiva dos corpos de prova, já com parâmetros estabelecidos, permitiu a obtenção de dados qualitativos para comparação entre as geometrias de ferramenta utilizadas, bem como com o processo MIG. Para estas soldas foram utilizados corpos de prova com $80 \times 200 \mathrm{~mm}$, tamanho adequado para a realização dos ensaios para obtenção das propriedades mecânicas da junta.

Tabela 1. Resultados dos ensaios mecânicos da liga AA 5052H34.

\begin{tabular}{l|l|l}
\hline \multirow{2}{*}{ Propriedades Mecânicas } & \multicolumn{2}{|l}{ Metal Base } \\
\cline { 2 - 3 } & Média & Desvio Padrão \\
\hline$\sigma_{\text {esc }}[\mathrm{MPa}]$ & 142,4 & 3,44 \\
\hline$\sigma_{\max }[\mathrm{MPa}]$ & 235,2 & 0,84 \\
\hline$\varepsilon[\%]$ & 24,2 & 0,45 \\
\hline Micro-dureza [HV 0.1] & 75,3 & 3,6 \\
\hline
\end{tabular}

Nota: $\sigma_{\text {esc }}$ - tensão de escoamento; $\sigma_{\max }$ - tensão máxima; $\varepsilon$ - alongamento (relativo a $25 \mathrm{~mm}$ ).

\subsection{Ferramentas de soldagem FSW}

Para a soldagem FSW três ferramentas com geometrias de pino distintas foram projetadas e fabricadas. As geometrias de pino escolhidas foram a cônica lisa (C), cônica com rosca (R) e facetada (F). A Figura 1 mostra em detalhe as ferramentas fabricadas para a soldagem através do processo FSW. 


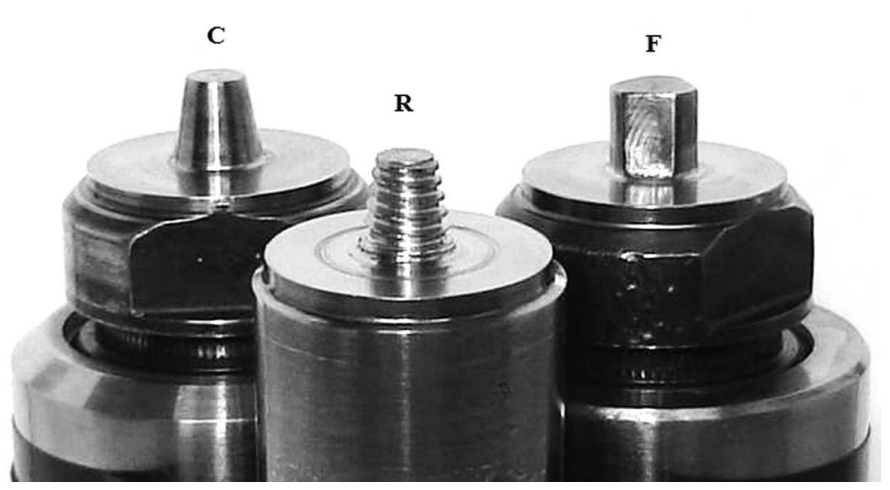

Figura 1. Ferramentas de soldagem FSW.

As características dimensionais de projeto das ferramentas basearam-se inicialmente nas informações disponíveis na literatura. Segundo diversos autores, as dimensões básicas para uma ferramenta FSW devem contemplar um diâmetro de pino similar à espessura da chapa a ser soldada. $\mathrm{O}$ comprimento do pino deve ser um pouco inferior à espessura da chapa, já que a região soldada abaixo da ponta do pino estende-se por uma pequena região apenas. Além disto, o diâmetro do ombro deve corresponder à aproximadamente três vezes o diâmetro maior do pino [3-7].

Como material para as ferramentas, utilizou-se aço AISI H13 temperado e revenido para uma dureza de $50 \mathrm{HRC}$ (ferramentas $\mathrm{C}$ e F) e aço AISI M2 sem tratamento térmico (ferramenta $\mathrm{R}$ ).

\subsection{Testes preliminares}

Como forma de definir parâmetros adequados para a realização de soldas com qualidade aceitável, inúmeros testes preliminares foram efetuados. As observações e melhorias implementadas a partir destes pré-testes basearam-se nos fatores descritos a seguir:

- Tamanho da rebarba

- Descontinuidade visível (inspeção visual e metalografia)

- Visualização da linha de solda na raiz (penetração total)

Os parâmetros adotados nos pré-testes, em especial a velocidade de rotação, basearam-se em informações disponíveis na literatura e em experiências anteriores conduzidas junto ao Grupo de Projeto, Fabricação e Automação Industrial - GPFAI/ UFRGS [8,9].

As soldas preliminares foram realizadas em chapas com dimensões de 30 x $200 \mathrm{~mm}$. Após a limpeza com solvente industrial e fixação no suporte de soldagem, soldas foram executadas para cada geometria de ferramenta fabricada. Inicialmente, procurou-se observar a influência da velocidade de rotação. As velocidades de rotação testadas $(630$ - 800 1000 RPM) são valores fixos da máquina, não sendo possível o uso de rotações intermediárias. Os parâmetros utilizados são os descritos na Tabela 2 .

Tabela 2. Parâmetros testados nos ensaios preliminares - ângulo de inclinação fixo.

\begin{tabular}{lllll}
\hline \multirow{2}{*}{ Ferramenta } & $\begin{array}{l}\text { Velocidade de } \\
\text { Soldagem [mm/min] }\end{array}$ & $\begin{array}{l}\text { Angulo de } \\
\text { Inclinação }\left[^{\circ}\right]\end{array}$ & $\begin{array}{l}\text { Velocidades de } \\
\text { Rotação [RPM] }\end{array}$ & $\begin{array}{l}\text { Penetração do } \\
\text { Ombro [mm }]\end{array}$ \\
\hline \hline $\mathrm{C}$ & 75 & 1 & $630 / 800 / 1000$ & 0,60 \\
$\mathrm{~F}$ & 75 & 1 & $630 / 800 / 1000$ & 0,55 \\
$\mathrm{R}$ & 75 & 1 & $630 / 800 / 1000$ & 0,70 \\
\hline
\end{tabular}

Tabela 3. Parâmetros testados nos ensaios preliminares - RPM fixa.

\begin{tabular}{llll}
\hline \hline \multirow{2}{*}{ Ferramenta } & $\begin{array}{l}\text { Velocidade de } \\
\text { Soldagem }[\mathrm{mm} / \mathrm{min}]\end{array}$ & $\begin{array}{l}\text { Ângulos de } \\
\text { Inclinação }\left[^{\circ}\right]\end{array}$ & $\begin{array}{l}\text { Velocidade de } \\
\text { Rotação [RPM] }\end{array}$ \\
\hline $\mathrm{C}$ & 75 & 2 e 3 & 1000 \\
$\mathrm{~F}$ & 75 & 2 e 3 & 1000 \\
$\mathrm{R}$ & 75 & 2 e 3 & 1000 \\
\hline
\end{tabular}

Tabela 4. Detalhes dimensionais das ferramentas de soldagem.

\begin{tabular}{cccccc}
\hline $\begin{array}{c}\text { Ferramenta / } \\
\text { Geometria }\end{array}$ & $\begin{array}{c}\text { Comprimento } \\
\text { pino }[\mathrm{mm}]\end{array}$ & $\begin{array}{c}\varnothing \text { do pino } \\
{[\mathrm{mm}]}\end{array}$ & $\begin{array}{c}\text { Geometria } \\
\text { do ombro }\end{array}$ & $\begin{array}{c}\varnothing \text { do ombro } \\
{[\mathrm{mm}]}\end{array}$ & Observações \\
\hline $\mathrm{C}$ - cônica lisa & 6,25 & 6,0 & Liso - reto & 18 & $\alpha=10^{\circ}$ \\
\hline $\mathrm{F}$ - facetada & 6,10 & 6,0 & Liso - reto & 18 & $120^{\circ}$ entre faces \\
\hline $\mathrm{R}-$ cônica com rosca & 6,20 & 6,0 & Liso - reto & 18 & $\alpha=10^{\circ} / \mathrm{passo} 1 \mathrm{~mm}$ \\
\hline
\end{tabular}

Notas: $\varnothing$ - diâmetro; $\alpha$ - ângulo de inclinação do pino. 
Após a soldagem, amostras da seção transversal dos corpos de prova foram analisadas em microscópio. Em um segundo momento, novos testes foram realizados observando-se a influência do ângulo de inclinação da ferramenta. Os parâmetros utilizados são os descritos na Tabela 3.

A velocidade de penetração utilizada nos ensaios foi a menor disponível na máquina fresadora e foi mantida constante em todos os ensaios em $10 \mathrm{~mm} / \mathrm{min}$, de forma a diminuir os esforços sobre os mancais do cabeçote.

A análise visual dos cordões de solda e das macrografias da seção transversal obtidas com as diferentes combinações de parâmetros, em conjunto com uma análise geométrica do problema, permitiu que correções dimensionais fossem feitas nas ferramentas de soldagem, de modo que as dimensões efetivamente utilizadas fossem modificadas para as descritas na Tabela 4.

\subsection{Soldagem FSW}

Uma vez definidos os parâmetros adequados, foram soldadas chapas de $80 \times 200 \mathrm{~mm}$ em junta de topo, de forma a permitir a retirada de corpos de prova para ensaios de dobramento e tração, além da análise metalográfica e microdureza.

A soldagem das chapas de alumínio através do processo FSW foi realizada em uma máquina fresadora universal convencional da marca Invicta, modelo FU2, ano de fabricação 1961. A máquina possui um motor de 7,5 HP, cuja transmissão é feita por quatro correias flexíveis. A velocidade máxima de rotação no cabeçote vertical é de 1200 RPM e a velocidade de avanço máxima da mesa é de 790 mm/min.
O suporte de soldagem (Figura 2) no qual as chapas são fixadas impede o afastamento das faces laterais durante a soldagem e também a movimentação vertical das mesmas, posicionando-as de forma adequada a soldagem.

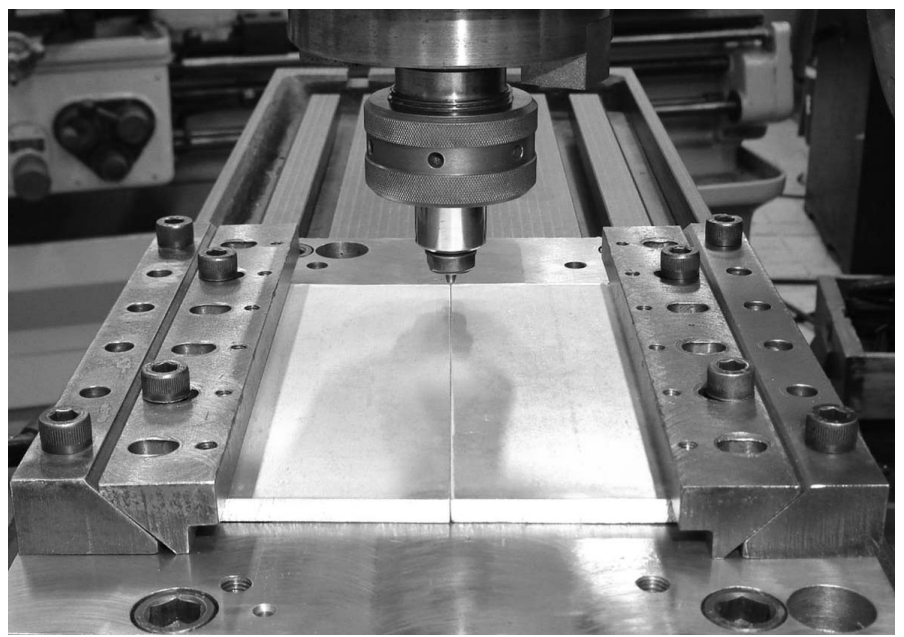

Figura 2. Suporte de fixação das chapas.

Cada ferramenta produziu três soldas segundo parâmetros idênticos de soldagem definidos a partir dos pré-testes. A escolha de parâmetros idênticos para as três ferramentas permite a comparação dos resultados em função da geometria de cada ferramenta.

A Tabela 5 apresenta os parâmetros de soldagem utilizados.

Tabela 5. Parâmetros utilizados na soldagem das chapas pelo processo FSW.

\begin{tabular}{lllll}
\hline \multirow{2}{*}{ Ferramenta } & $\begin{array}{l}\text { Ângulo de } \\
\text { Inclinação }\left[{ }^{\circ}\right]\end{array}$ & $\begin{array}{l}\text { Velocidade de } \\
\text { Soldagem }[\mathrm{mm} / \mathrm{min}]\end{array}$ & $\begin{array}{l}\text { Velocidade de } \\
\text { Rotação }[\mathrm{RPM}]\end{array}$ & $\begin{array}{l}\text { Penetração do } \\
\text { ombro [mm] }\end{array}$ \\
\hline $\mathrm{C}$ & 3 & 75 & 1000 & $\sim 0,40$ \\
$\mathrm{~F}$ & 3 & 75 & 1000 & $\sim 0,45$ \\
$\mathrm{R}$ & 3 & 75 & 1000 & $\sim 0,45$ \\
\hline
\end{tabular}

As chapas foram soldadas em temperatura ambiente, sem pré ou pós-aquecimento do material. Durante a soldagem monitorouse o comportamento da velocidade de rotação da ferramenta.

\subsection{Soldagem MIG}

A soldagem pelo processo MIG foi realizada de forma semi-automática na posição plana. Utilizou-se um dispositivo mecanizado de movimentação linear com velocidade constante como meio de produzirem-se soldas com propriedades uniformes e com boa repetitividade (Figura 3 ).

Na Tabela 6 são apresentados os parâmetros de soldagem utilizados na soldagem dos corpos de prova após os devidos ajustes iniciais.

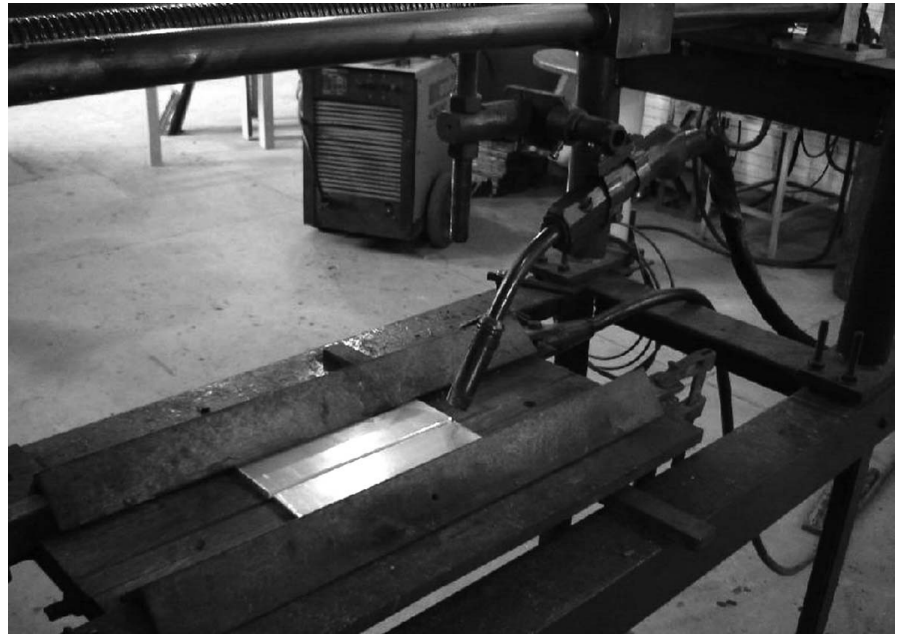

Figura 3. Dispositivo utilizado na soldagem MIG semiautomática. 
Tabela 6. Parâmetros de soldagem MIG.

\begin{tabular}{|c|c|}
\hline Diâmetro do bocal & $15 \mathrm{~mm}$ \\
\hline Diâmetro do arame & $1,2 \mathrm{~mm}$ \\
\hline Dist. peça - bico de contato & $20 \mathrm{~mm}$ \\
\hline Velocidade de alimentação do arame & $8 \mathrm{~m} / \mathrm{min}$ \\
\hline
\end{tabular}

\begin{tabular}{ll}
\hline Corrente (CCEP) & $150-165 \mathrm{~A}$ \\
\hline Tensão & $23-25 \mathrm{~V}$ \\
\hline Vazão de Argônio & 15 1/min \\
\hline Velocidade de Soldagem & $265 \mathrm{~mm} / \mathrm{min}$ \\
\hline \hline
\end{tabular}

A velocidade de soldagem utilizada, embora inferior àquelas sugeridas pela literatura, permitiu a soldagem em um passe único. Para maior proteção da região próxima ao arco elétrico, a soldagem ocorreu com a tocha sob um ângulo de deslocamento negativo de $45^{\circ}$, "empurrando" a poça de fusão.

Como metal de adição utilizou-se o arame AWS A5.10 ER5356. De forma similar ao realizado no processo FSW, três soldas foram produzidas segundo parâmetros idênticos. Após a soldagem, corpos de prova foram usinados para realização de ensaios mecânicos e análise metalográfica.

\section{Resultados e discussão}

\subsection{Testes preliminares - FSW}

Nesta fase do trabalho buscou-se identificar a influência da velocidade de rotação sobre a qualidade da junta resultante, sendo esta avaliação feita em modo qualitativo. Amostras da seção transversal das juntas soldadas com as diferentes geometrias de ferramenta foram preparadas e analisadas em microscópio.

A Figura 4 apresenta a seção transversal obtida utilizando-se a geometria cônica lisa em combinação com os parâmetros de pré-teste.

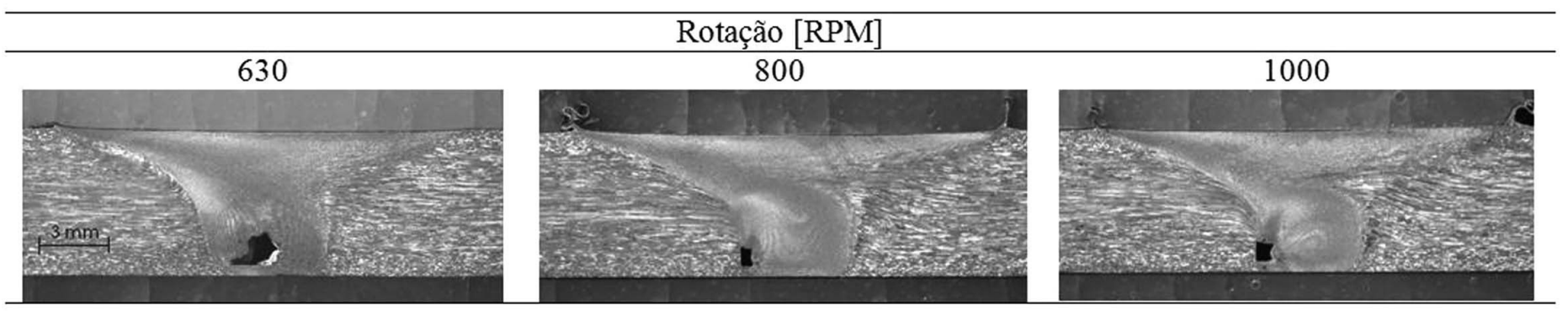

Figura 4. Macrografia (Reagente Tuckers) - Ferramenta de pino cônico liso.

Em todas as macrografias é possível identificar uma assimetria em relação à linha central da junta soldada, provocada pela combinação dos movimentos de translação e rotação da ferramenta. O lado da junta em que a velocidade tangencial (rotação) da ferramenta tem a mesma direção e sentido do seu deslocamento linear é denominado lado de avanço. As partículas do metal base situadas no lado de avanço tendem a se movimentar no sentido do deslocamento linear da ferramenta. De forma análoga, o lado oposto da junta, em que a velocidade tangencial tem a mesma direção e sentido oposto ao deslocamento linear da ferramenta, é denominado lado de recuo. No lado de recuo as partículas do metal base em contato com a ferramenta tendem a se movimentar em sentido oposto ao seu deslocamento linear.
Para todas as rotações testadas pode-se observar a presença de uma descontinuidade longitudinal ao cordão, localizada no lado de avanço próxima à raiz da solda e que se estende ao longo de todo o comprimento soldado. Nota-se que o aumento da rotação de 630 para 800 RPM ocasiona a diminuição do tamanho da descontinuidade, mas o aumento de 800 para 1000 RPM não apresenta o mesmo efeito de diminuição.

Em seguida, novas soldas foram feitas variando-se o ângulo de inclinação da ferramenta. As velocidades de rotação e avanço foram mantidas fixas em 1000 RPM e $75 \mathrm{~mm} / \mathrm{min}$. Na Figura 5 pode-se observar o efeito do aumento do ângulo de ataque sobre a formação da descontinuidade.

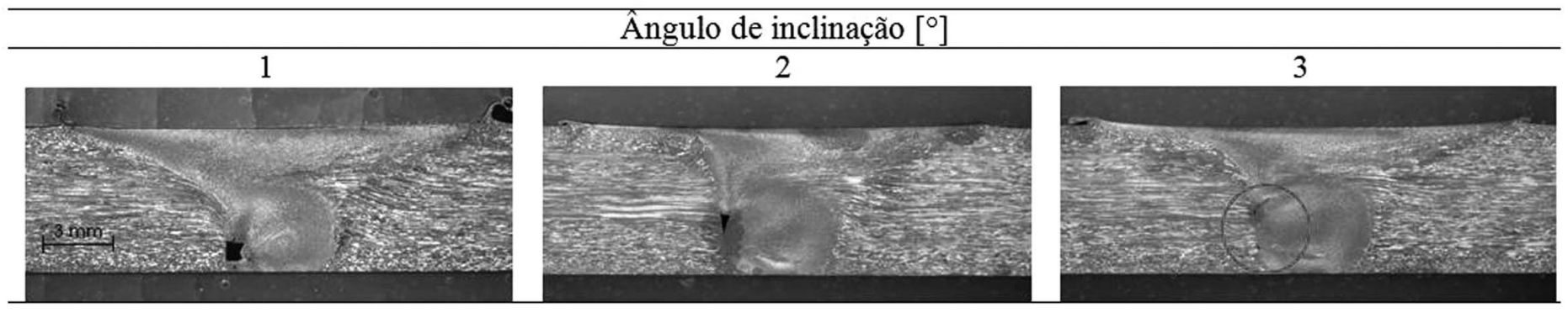

Figura 5. Diminuição no tamanho da descontinuidade com aumento do ângulo de ataque - Ferramenta de pino cônico liso. 
Observa-se a presença de uma descontinuidade longitudinal ao cordão, que se estende ao longo de todo o comprimento soldado. $\mathrm{O}$ aumento do ângulo de inclinação da ferramenta ocasiona forte redução no tamanho da descontinuidade formada, como ilustrado pela Figura 4. Entretanto, ainda è possível notar a formação deste defeito em todas as seções transversais, como destacado pelo círculo na seção correspondente à inclinação de três graus.

Para a ferramenta de geometria facetada, as seções transversais obtidas na fase de pré-teste são as apresentadas na Figura 6.

\begin{tabular}{cccc}
\hline \multicolumn{6}{c}{ Rotação [RPM] } \\
\hline 630 \\
\hline
\end{tabular}

Figura 6. Macrografia (Reagente Tuckers) - Ferramenta de pino facetado.

Embora todas as combinações utilizadas apresentem uma descontinuidade longitudinal ao longo do cordão, observa-se a tendência de diminuição do tamanho desta com o aumento da velocidade de rotação. Deve-se notar também que o formato do pino resultou em uma região soldada com aspecto diferente daquela observada para o pino cônico.
Diferentes ângulos de inclinação foram em seguida avaliados. As velocidades de rotação e avanço foram mantidas fixas em $1000 \mathrm{RPM}$ e $75 \mathrm{~mm} / \mathrm{min}$, respectivamente, e combinadas com ângulos de ataque de 2 e 3 graus.

A Figura 7 mostra a seção transversal da solda para as diferentes inclinações adotadas.

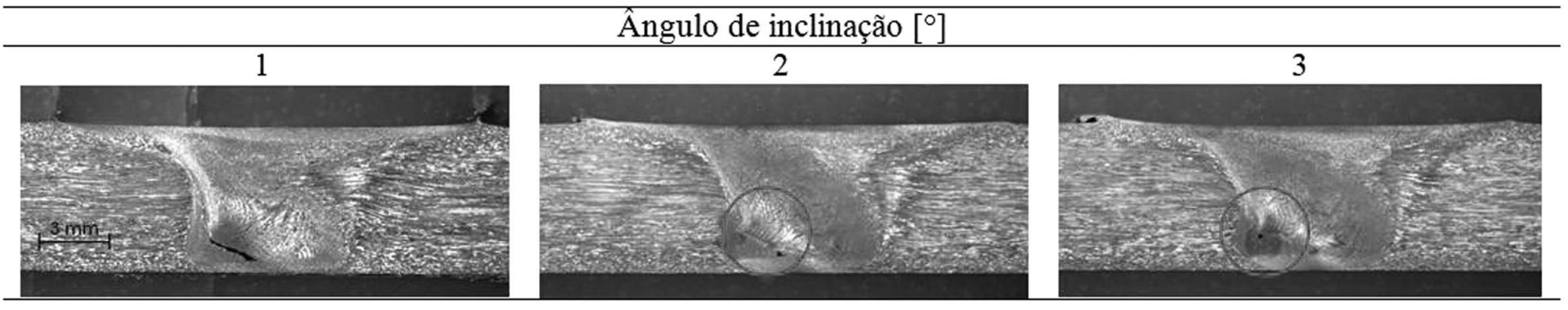

Figura 7. Diminuição no tamanho da descontinuidade com aumento do ângulo de ataque - Ferramenta de pino facetado.

Como observado nas soldas produzidas com a ferramenta de pino cônico liso, novamente nota-se a tendência de diminuição no tamanho do defeito formado segundo ângulos de inclinação maiores. No entanto não foi possível eliminar a descontinuidade por completo, como destacado pelos círculos (Figura 7).
Novamente, houve formação de rebarba em excesso, o que sugere correções no comprimento adotado para o pino.

Para a ferramenta de geometria cônica com rosca, as seções transversais resultantes da fase de pré-teste são as apresentadas na Figura 8.

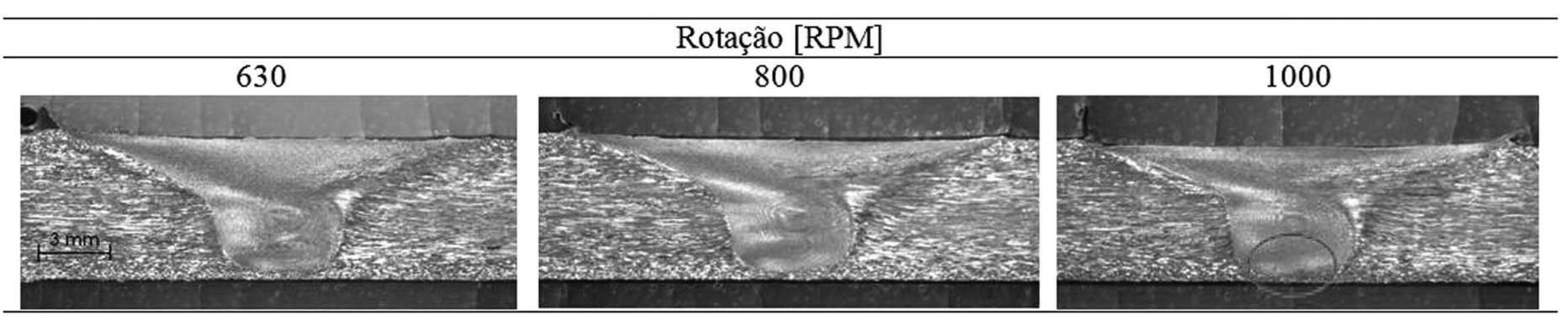

Figura 8. Macrografia (Reagente Tuckers) - Ferramenta de pino cônico com rosca com ângulo inclinação de $1^{\circ}$.

O desempenho da ferramenta com rosca mostrou-se superior às demais geometrias empregadas nos pré-testes mesmo para um ângulo de inclinação de $1^{\circ}$. Como é possível observar, não há presença de descontinuidade visível ao microscópio, mesmo utilizando-se maiores magnificações. A partir destas observações, ensaios com ângulos de ataque maiores não foram realizados visto que o efeito obtido com este aumento para as demais ferramentas atuou no sentido de melhorar a qualidade final da solda.

Da Figura 8 também se pode notar que penetração total não foi atingida (destacado na Figura) e que houve formação em excesso de rebarba. Como já comentado, ambos os problemas 
são causados pelo pequeno comprimento do pino em relação à espessura da chapa. Desta forma, o pino não se aproximou suficientemente da raiz e permitiu a penetração do ombro em excesso, formando a rebarba.

\subsection{Soldagem pelo processo FSW}

Uma vez definidos os parâmetros para a soldagem FSW e executados os devidos ajustes nas ferramentas, foram realizadas soldas em chapas maiores para posterior avaliação das propriedades mecânicas.

O gráfico da Figura 9 apresenta o comportamento da velocidade de rotação da ferramenta durante a soldagem.

O gráfico representa o comportamento padrão da velocidade de rotação durante a soldagem FSW para as três geometrias de ferramenta testadas na máquina fresadora. Este comportamento é vinculado à máquina utilizada e ao tipo de transmissão presente, e não necessariamente do processo de soldagem. Cinco regiões podem ser identificadas neste gráfico:

- Regiões 1 e 5, que representam a ferramenta em rotação livre, sem carga, respectivamente no início e fim da solda;

- Região 2, que demonstra a queda de rotação verificada no momento de penetração da ferramenta, com um decréscimo acentuado a partir do momento em que o ombro entra em contato com a chapa;

- Região 3, que representa o intervalo no qual modifica-se manualmente a velocidade de avanço da mesa por meio de alavancas, ocasionando um período de aquecimento estacionário (aproximadamente 10s) com conseqüente aumento da rotação;

- Região 4, que compreende o período no qual a ferramenta desloca-se ao longo da junta, formando a solda.

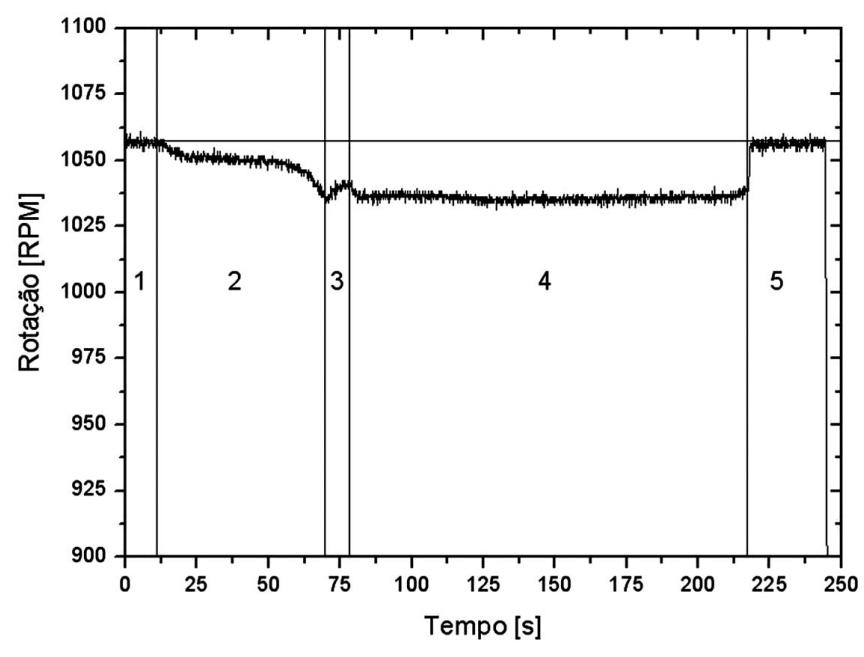

Figura 9. Comportamento da velocidade de rotação durante a soldagem.

Observa-se inicialmente que a rotação definida na máquina difere daquela medida na ferramenta, e que sem carga (regiões 1 e 5) a velocidade de rotação média é de 1056 RPM. A velocidade de rotação efetiva durante a soldagem é a observada na região 4 , indicando uma velocidade de rotação de 1035 RPM.

As três geometrias de ferramenta utilizadas produziram soldas de boa qualidade se analisadas do ponto de vista visual do cordão de solda, como pode ser visto na Figura 10.a. No furo remanescente da solda obtida com a ferramenta de geometria cônica lisa, entretanto, é possível observar a presença de uma descontinuidade, como mostra a Figura 10.b.
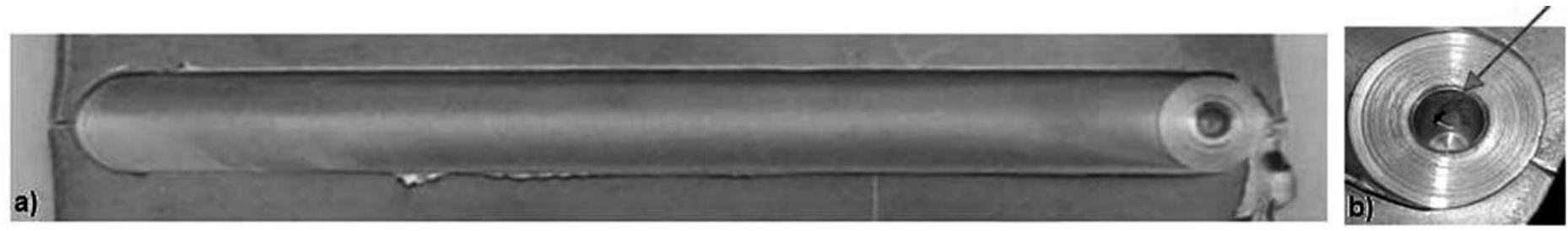

Figura 10. a) Aparência de um cordão obtido com a ferramenta com pino cônico com rosca. b) Descontinuidade observada no furo remanescente da solda realizada com ferramenta com pino cônico liso.

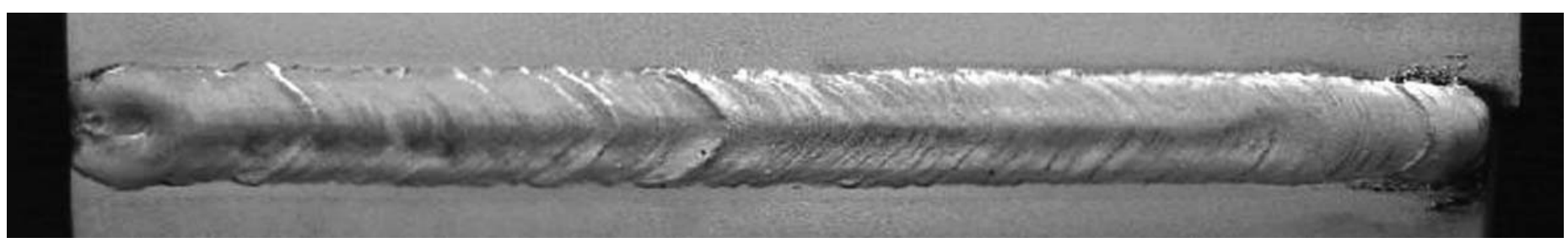

Figura 11. Aparência do cordão - processo MIG.

\subsection{Soldagem pelo processo MIG}

A Figura 11 apresenta a aparência de um dos cordões de solda obtidos através do processo MIG.

As soldas obtidas pelo processo MIG apresentaram boa aparência superficial e isenção de defeitos detectáveis sem auxílio de técnicas de inspeção adicionais não destrutivas, como o método dos líquidos penetrantes.

Descontinuidades como mordeduras (face ou raiz), falta de penetração ou falta de fusão não foram observados. Entretanto, considerável distorção angular pôde ser constatada em função do ciclo de aquecimento/resfriamento não uniforme com 
conseqüente dilatação/contração inerente ao processo de soldagem.

\subsection{Ensaio de dobramento}

Após a soldagem das chapas, corpos de prova foram preparados para o ensaio de dobramento, de acordo com a norma ASTM E 190 [10]. As chapas foram submetidas ao dobramento até apresentarem algum sinal de falha, ou caso isto não ocorresse, até um dobramento de $180^{\circ}$.

As chapas soldadas com a ferramenta de pino cônico liso não apresentaram qualquer defeito quando submetidas ao dobramento transversal de face. No dobramento transversal de raiz, entretanto, observou-se o surgimento de um defeito observado entre $25-35^{\circ}$ de dobramento, dependendo da solda em análise.

A Figura 12 apresenta em detalhe o defeito, que se estende longitudinalmente à solda. A posição da descontinuidade coincide com aquela verificada em inspeção visual (lado de avanço, próximo à raiz da solda).

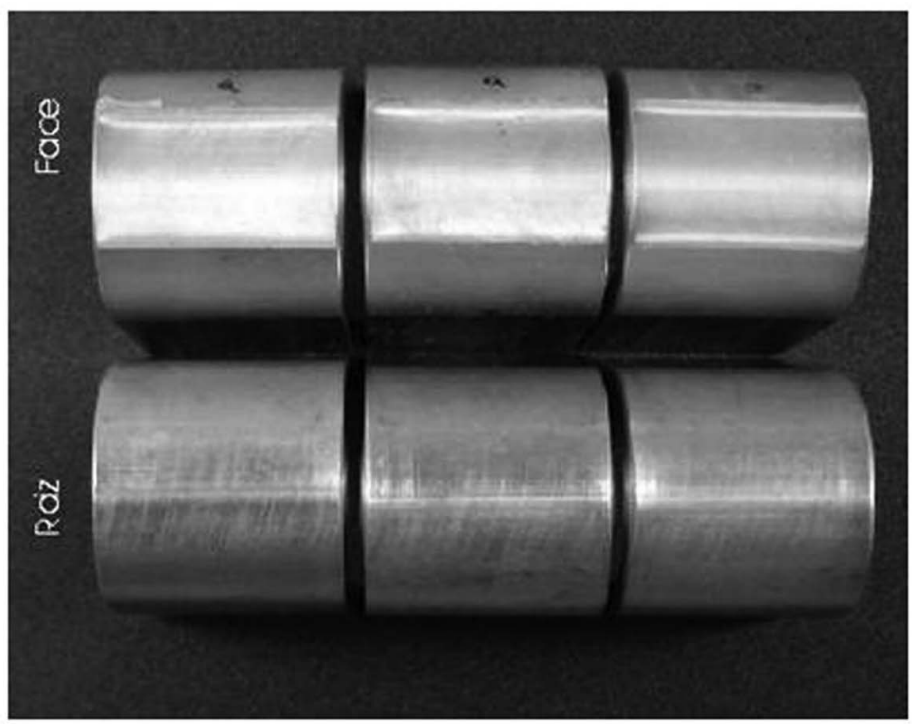

(a)

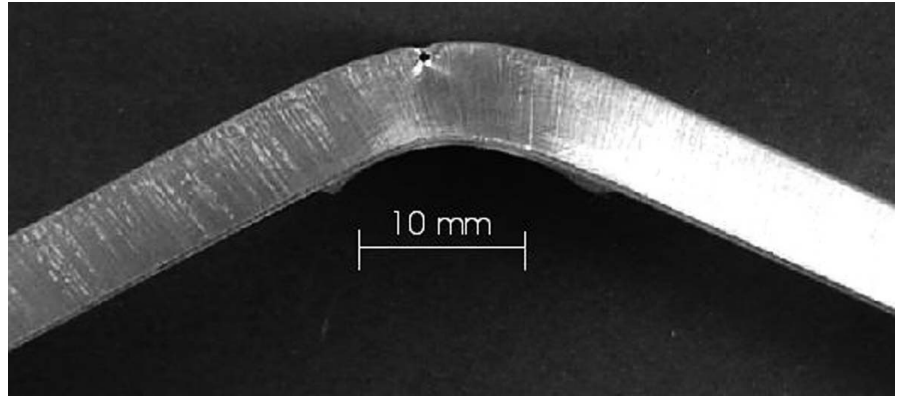

Figura 12. Defeito observado no dobramento transversal de raiz.

O dobramento transversal de face e de raiz dos corpos de prova soldados com demais geometrias não apresentaram quaisquer defeitos, tendo suportado um dobramento de $180^{\circ}$ como indicado pela Figura 13.

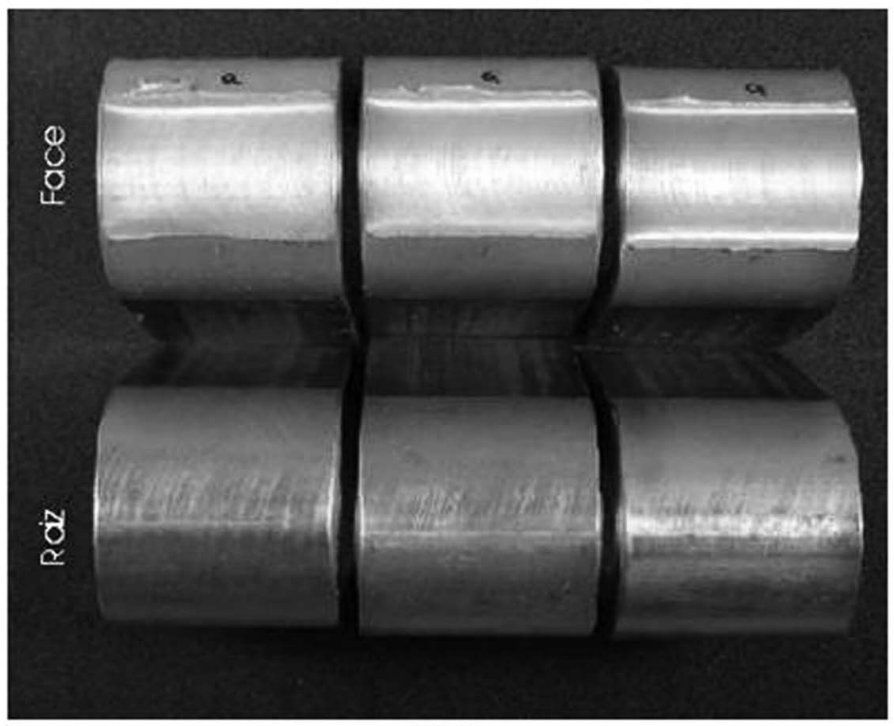

(b)

Figura 13. Dobramento de face e raiz. Ferramenta facetada (a) e cônica com rosca (b).

Com base nos testes de dobramento, nota-se que as soldas obtidas com as geometrias facetada e cônica com rosca não apresentam significativa queda de ductilidade do material em decorrência da presença da solda. Para a geometria cônica lisa, entretanto, verifica-se que novos ajustes de parâmetros ou dimensionais seriam necessários para que as soldas obtidas com esta geometria fossem aprovadas em ensaio de dobramento.

O mesmo procedimento foi adotado para os corpos de prova obtidos através do processo MIG. No dobramento transversal de face não se detectou a presença de trincas ou defeitos superficiais. Entretanto, no dobramento transversal de raiz, pode-se observar a abertura de poros na superfície externa ao dobramento, como mostra a Figura 14.

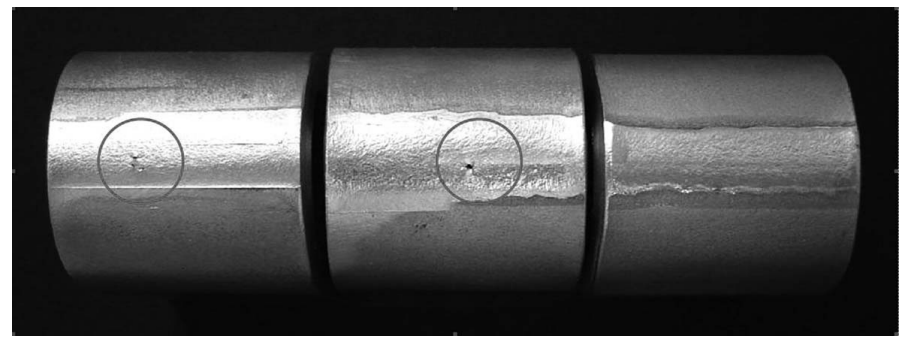

Figura 14. Dobramento transversal de raiz.

O surgimento destas descontinuidades, entretanto, não impediu o dobramento completo dos corpos de prova, fato não observado nas amostras soldadas pelo processo FSW utilizando a ferramenta de geometria cônica lisa. Possivelmente a ocorrência 
destes poros deve-se à retenção de hidrogênio no interior da poça de fusão, devido a uma má proteção da poça ou mesmo a presença de umidade no gás de proteção.

\subsection{Ensaios de tração}

Os ensaios de tração foram realizados de acordo com a norma ASTM E8M [11]. A Tabela 7 apresenta os valores obtidos no ensaio de tração das amostras soldadas com a ferramenta de geometria cônica lisa.

Tabela 7. Ensaio de tração - Ferramenta com pino cônico liso.

\begin{tabular}{llll}
\hline $\begin{array}{l}\text { Propriedades } \\
\text { Mecânicas }\end{array}$ & $\bar{C}$ & $s$ & $\begin{array}{l}\text { Eficiência Mecânica } \\
\text { da Junta [\%] }\end{array}$ \\
\hline $\bar{\sigma}_{\text {esc }[\mathrm{MPa}]}$ & 115,11 & 11,83 & 80,8 \\
$\bar{\sigma}_{\max }[\mathrm{MPa}]$ & 212,67 & 3,35 & 90,4 \\
$\bar{\varepsilon}[\%]$ & 18,22 & 1,30 & 75,3 \\
\hline \hline
\end{tabular}

Nota: $\bar{C}$ - valor médio obtido; s - desvio padrão.

Segundo os dados obtidos, inicialmente observa-se que a tensão de escoamento apresenta um desvio-padrão grande, o que indica a existência de uma heterogeneidade nos corpos de prova ensaiados. Este desvio-padrão pode estar ligado a variações na descontinuidade presente nestas soldas, o que se traduz por uma disparidade nos resultados da tensão de escoamento média de cada repetição.

Embora o desvio-padrão da tensão de escoamento indique baixa repetitividade das propriedades finais da junta, esta geometria de ferramenta alcançou uma eficiência mecânica média em torno de $80 \%$ do metal base. Como já verificado através dos ensaios de dobramento, observa-se queda acentuada da ductilidade, demonstrada através da redução do alongamento.

Durante os ensaios de tração, observou-se que a falha dos corpos de prova origina-se muito próxima ao defeito previamente mencionado, propagando-se com o aumento da tensão e rompendo no próprio cordão de solda, como mostra a Figura 15.

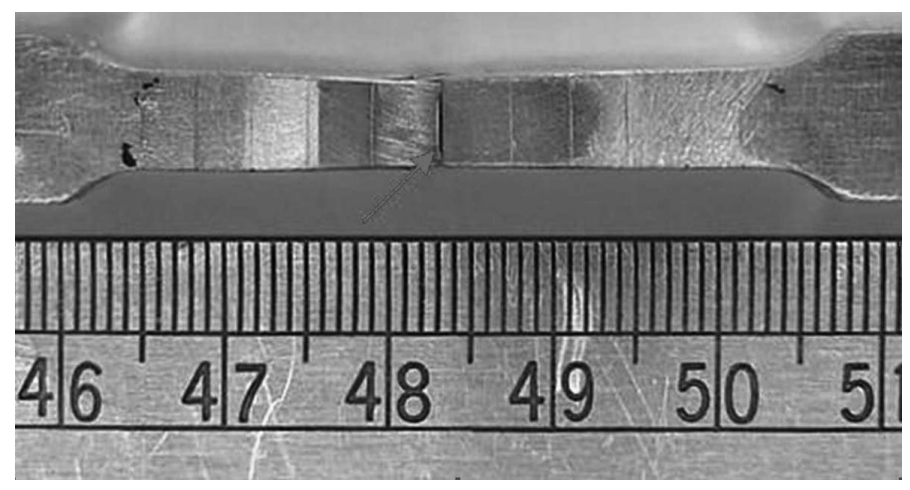

Figura 15. Ruptura sobre o cordão de solda FSW - geometria cônica lisa.
Na Tabela 8 são apresentados os resultados obtidos para a ferramenta de geometria facetada. De forma semelhante ao obtido pela geometria cônica lisa, a eficiência mecânica das soldas para esta geometria apresentou desempenho de $81 \%$, porém com desvio-padrão menor. Isto demonstra que o processo teve boa repetitividade, como indicado pelos valores médios de tensão de escoamento em cada repetição.

Tabela 8. Ensaio de tração - Ferramenta com pino facetado.

\begin{tabular}{llll}
\hline \hline $\begin{array}{l}\text { Propriedades } \\
\text { Mecânicas }\end{array}$ & $\bar{F}$ & $s$ & $\begin{array}{l}\text { Eficiência Mecânica da } \\
\text { Junta [\%] }\end{array}$ \\
\hline $\bar{\sigma}_{\text {esc }}[\mathrm{MPa}]$ & 116,33 & 2,18 & 81,7 \\
$\bar{\sigma}_{\max }[\mathrm{MPa}]$ & 221,67 & 2,12 & 94,3 \\
$\bar{\varepsilon}[\%]$ & 24,78 & 1,39 & 102,4 \\
\hline
\end{tabular}

Nota: $\bar{F}$ - valor médio obtido; s - desvio padrão.

Embora a eficiência mecânica da junta seja bastante próxima daquela apresentada pela geometria cônica lisa, o desempenho desta ferramenta mostra-se superior quando se compara a ductilidade dos corpos de prova soldados. O alongamento obtido utilizando-se a geometria facetada mostra-se comparável à do metal base, sem demonstrar perda significativa.

Quanto ao local de ruptura dos corpos de prova, observou-se que a falha ocorre sobre a solda no lado de recuo, como ilustrado pela Figura 16, situando-se a uma distância entre 5 e $8 \mathrm{~mm}$ afastada da linha de união das chapas.

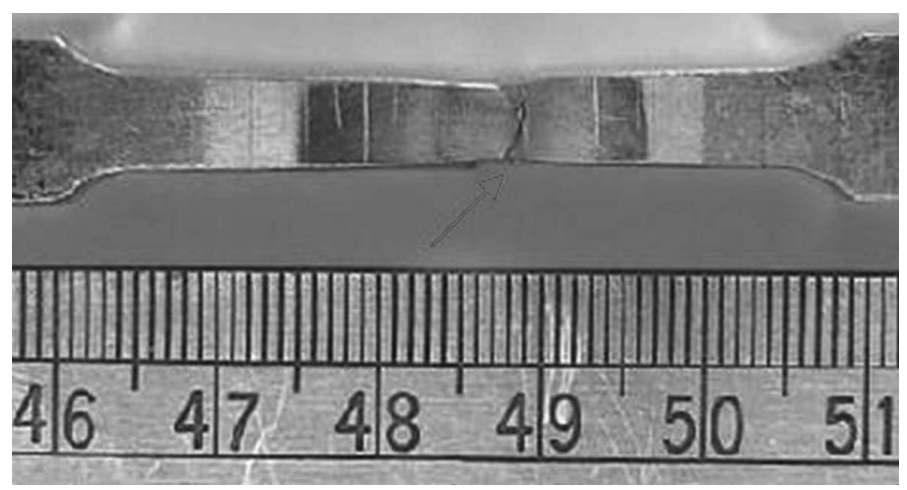

Figura 16. Ruptura sobre o cordão de solda FSW - geometria facetada.

Os resultados obtidos em ensaio de tração para a ferramenta de geometria cônica com rosca são apresentados na Tabela 9. Notase que a eficiência mecânica da solda obtida com o emprego da geometria cônica com rosca é muito próxima daquela alcançada pelas demais geometrias.

Embora com desempenho superior quanto à tensão de escoamento e tensão máxima, as soldas obtidas pelo uso desta geometria apresentaram uma queda de aproximadamente $10 \%$ no alongamento. Este resultado, porém, não chegou a comprometer o desempenho das soldas nos ensaios de dobramento. Para as três grandezas avaliadas, um pequeno desvio-padrão foi obtido 
mostrando que o processo apresentou boa repetitividade.

Tabela 9 - Ensaio de tração - Ferramenta com pino cônico com rosca.

\begin{tabular}{llll}
\hline $\begin{array}{l}\text { Propriedades } \\
\text { Mecânicas }\end{array}$ & $\bar{R}$ & $s$ & $\begin{array}{l}\text { Eficiência Mecânica } \\
\text { da Junta [\%] }\end{array}$ \\
\hline $\bar{\sigma}_{\text {esc }}[\mathrm{MPa}]$ & 117,00 & 5,59 & 82,2 \\
$\bar{\sigma}_{\max }[\mathrm{MPa}]$ & 223,78 & 2,05 & 95,1 \\
$\bar{\varepsilon}[\%]$ & 22,22 & 0,67 & 91,8 \\
\hline
\end{tabular}

Nota: $\bar{R}$ - valor médio obtido; $\mathrm{s}$ - desvio padrão.

O local da ruptura observado encontra-se sobre o cordão, novamente não se observando a origem da falha sobre a raiz da solda, mas sim nas adjacências desta no lado de recuo, como mostra a Figura 17. Assim como para a geometria facetada, a ruptura ocorre numa faixa situada entre 5 e $8 \mathrm{~mm}$ de distância da linha de centro da solda.

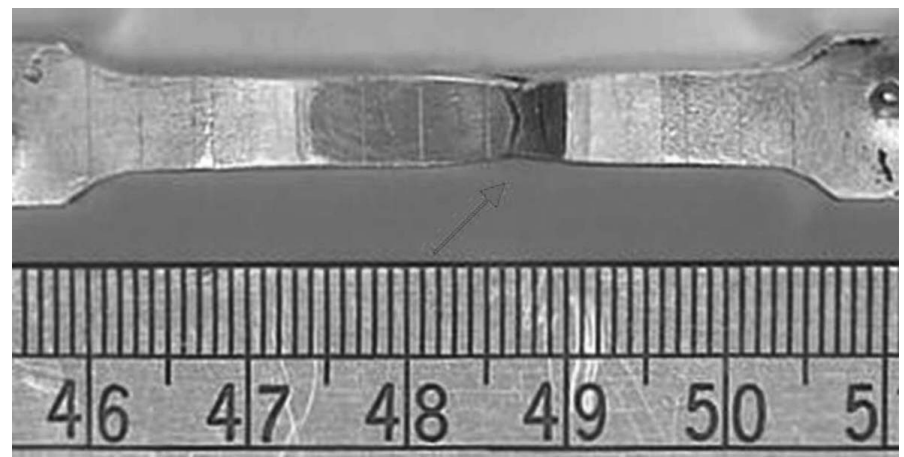

Figura 17. Ruptura sobre o cordão de solda FSW - geometria cônica com rosca.

Com exceção dos corpos de prova soldados pelo processo FSW e obtidos com o emprego da ferramenta de geometria cônica lisa, as demais rupturas observadas nos ensaios de tração se aproximam dos resultados encontrados por Larsson et. al. [12].

Na soldagem de alumínio 5083 através do processo FSW, Larsson observou que a ruptura dos corpos de prova ocorre sobre o cordão e se origina em uma região de interface entre núcleo da solda e metal base.

Para o processo MIG, os valores obtidos nos ensaios de tração são os mostrados na Tabela 10.

Verifica-se que as juntas obtidas pelo processo MIG apresentam desempenho medianamente inferior àquele observado para as juntas obtidas através do processo FSW, se comparadas em termos da tensão de escoamento ou da tensão máxima. Entretanto, considerando-se o desvio-padrão das amostras pode-se afirmar que o desempenho obtido por ambos os processos é similar.

Tabela 10. Ensaio de tração - solda MIG.

\begin{tabular}{llll}
\hline $\begin{array}{l}\text { Propriedades } \\
\text { Mecânicas }\end{array}$ & $\bar{M}$ & $s$ & $\begin{array}{l}\text { Eficiência Mecânica } \\
\text { da Junta [\%] }\end{array}$ \\
\hline $\bar{\sigma}_{e s c}[\mathrm{MPa}]$ & 106,67 & 8,87 & 74,9 \\
$\bar{\sigma}_{\max }[\mathrm{MPa}]$ & 209,11 & 11,69 & 88,9 \\
$\bar{\varepsilon}[\%]$ & 20,67 & 4,21 & 85,4 \\
\hline
\end{tabular}

Nota: $\bar{M}$ - valor médio obtido; s - desvio padrão.

Levando-se em conta o alongamento, a eficiência mecânica da junta obtida com o processo MIG assemelha-se àquela verificada na soldagem FSW com ferramenta de geometria cônica com rosca. Com relação ao local de ruptura, observou-se que a falha ocorre ao lado do cordão de solda, na zona afetada pelo calor, como mostra a Figura 18.

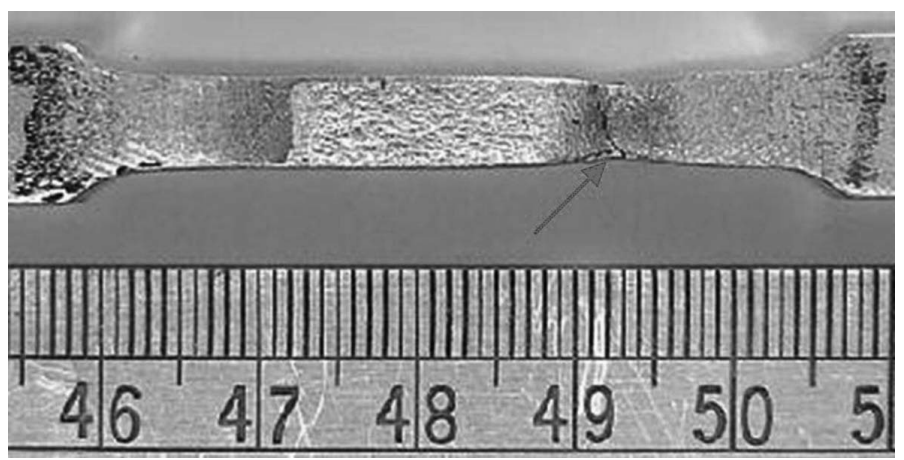

Figura 18. Ruptura ao lado do cordão de solda MIG.
(A)

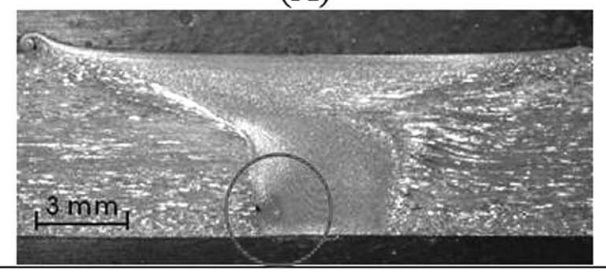

(B)

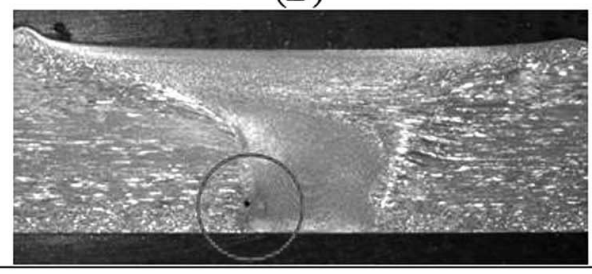

(C)

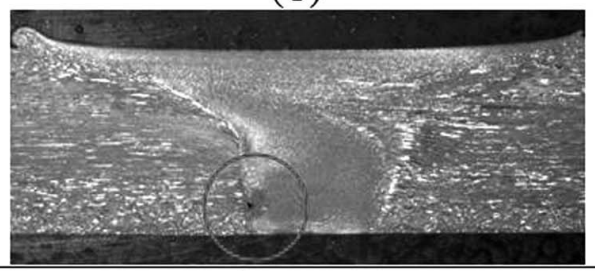

Figura 19. Amostras da seção transversal - ferramenta de soldagem cônica lisa. 


\subsection{Análise macrográfica}

A Figura 19 apresenta amostras da seção transversal da solda obtida pelo processo FSW com a ferramenta cônica lisa. Estas amostras representam respectivamente o início (A), meio (B) e fim (C) do cordão de solda.

Embora a penetração da ferramenta tenha sido completa, nota-se a presença de uma pequena descontinuidade localizada no lado de avanço da ferramenta, próxima à raiz da solda (círculos), que se estende ao longo de toda a junta, como evidenciado pelos cortes transversais realizados ao longo do cordão. A localização coincide com aquela na qual se observou o surgimento de defeito durante o ensaio de dobramento.

A Figura 20 apresenta amostras da seção transversal de uma solda produzida com a ferramenta de geometria facetada.

Não se observam descontinuidades similares àquelas produzidas pela geometria cônica lisa. Verifica-se que o núcleo da solda é consideravelmente maior que aquele produzido pela geometria cônica. Isto se deve ao fato do pino facetado não possuir uma conicidade como as demais ferramentas. Por fim, a Figura 21 apresenta as macrografias das seções transversais de uma das chapas soldadas com a geometria cônica com rosca.

De forma semelhante à geometria facetada, não há ocorrência de descontinuidades. Pode-se notar que a microestrutura resultante no núcleo da solda possui grãos bastante refinados e com distribuição homogênea, quando comparados às demais seções transversais analisadas. O núcleo da solda apresenta-se com um formato aproximadamente circular, e o efeito da adição dos filetes de rosca ao pino cônico propicia um aumento do tamanho da região de mistura, se comparado à seção transversal da solda obtida com o emprego da ferramenta de soldagem cônica lisa. Na Figura 22 podem-se observar amostras representativas do início, meio e final de uma das soldas obtidas com o processo MIG.
(A)

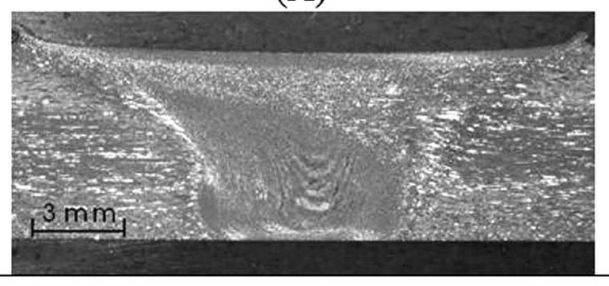

(B)

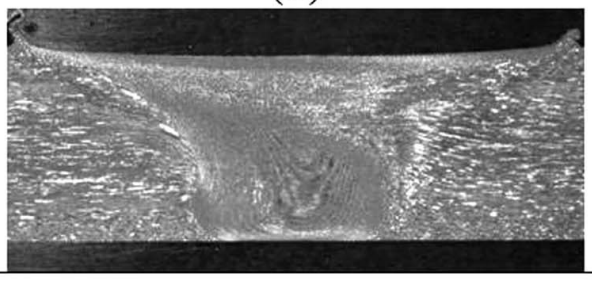

(C)

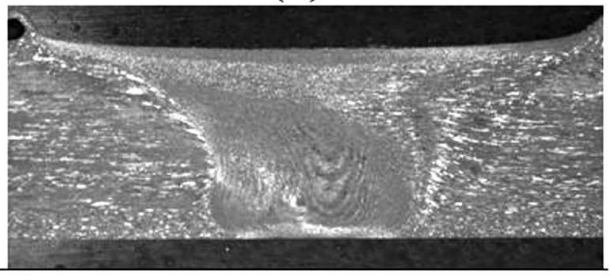

Figura 20. Amostras da seção transversal - ferramenta de soldagem facetada.

(A)

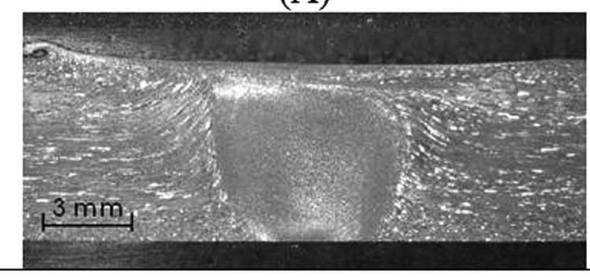

(B)

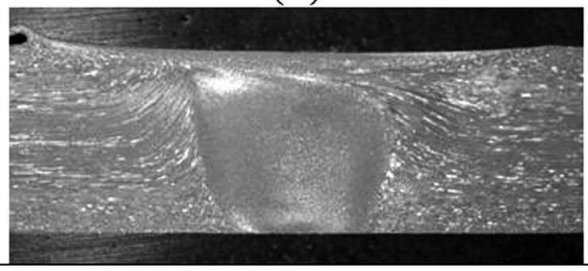

(C)

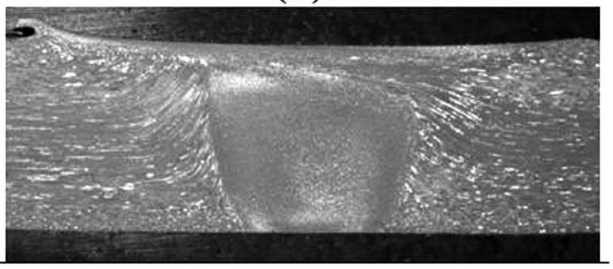

Figura 21. Amostras da seção transversal - ferramenta de soldagem cônica com rosca.

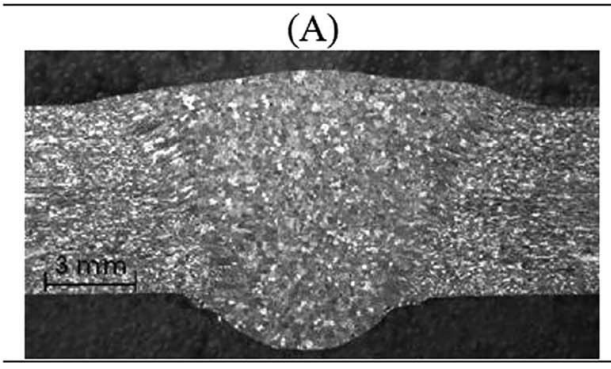

(B)

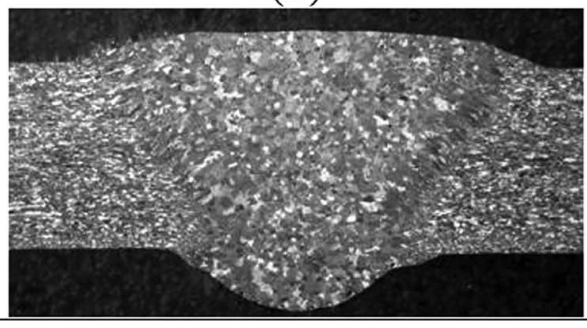

(C)

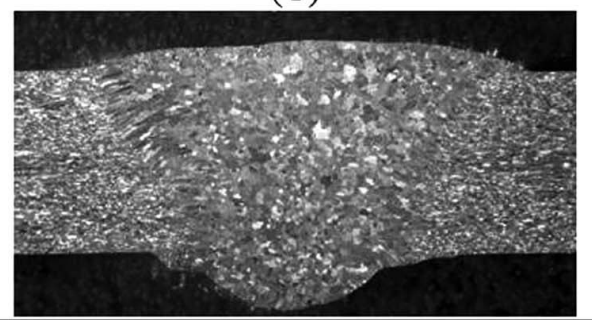

Figura 22. Amostras da seção transversal - solda MIG.

Nota-se a grande disparidade entre os tamanhos de grão na zona fundida e no metal base em decorrência da deposição do metal de adição e das elevadas temperaturas a que o material foi submetido, com conseqüentes transformações microestruturais. Com maiores magnificações verifica-se a presença de porosidade dispersa ao longo da zona fundida, fato que vem a influenciar o desempenho dos corpos de prova no ensaio de tração.

\subsection{Perfis de dureza}

As Figuras 23 à 26 apresentam os gráficos que mostram os valores de microdureza encontrados na seção transversal das soldas produzidas através dos processos FSW e MIG. Cada ponto representa a média do valor de microdureza na posição "x" da seção tranversal, com seu respectivo desvio-padrão.

Nestes gráficos, o ponto zero indica a linha central da solda, sendo o sentido de x positivo o lado de recuo da ferramenta. A 
linha horizontal representa a dureza média do metal base $(75,3$ HV).

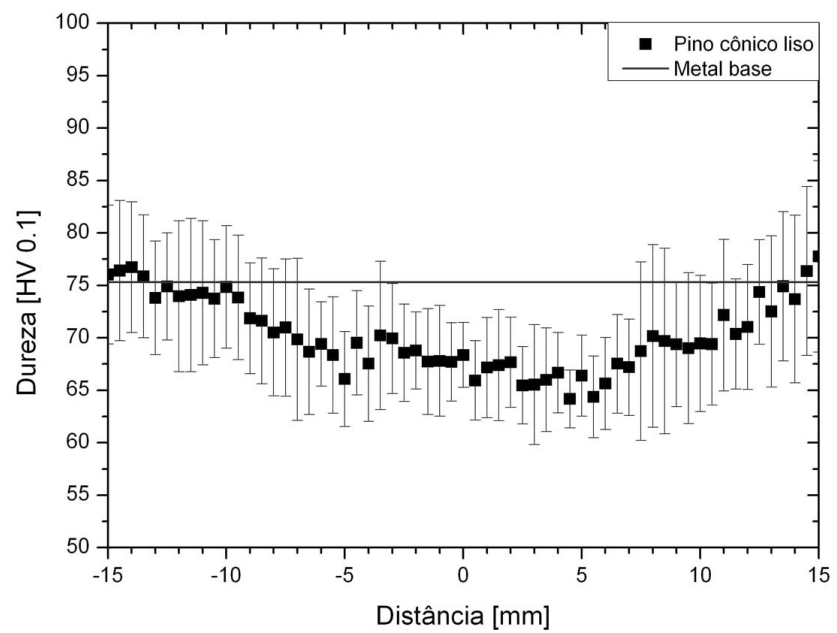

Figura 23. Perfil de microdureza médio - ferramenta cônica lisa.

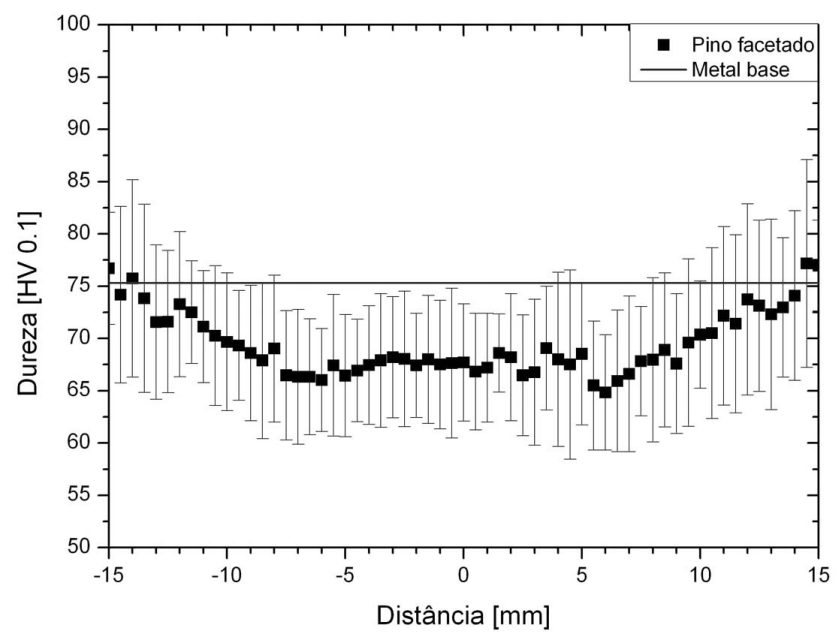

Figura 24. Perfil de microdureza médio - ferramenta facetada.

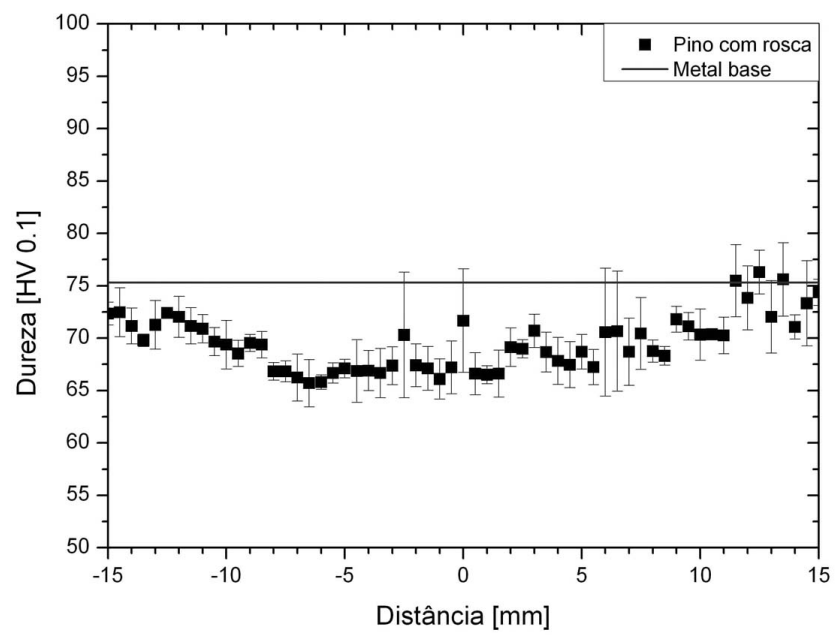

Figura 25. Perfil de microdureza médio - ferramenta cônica com rosca.

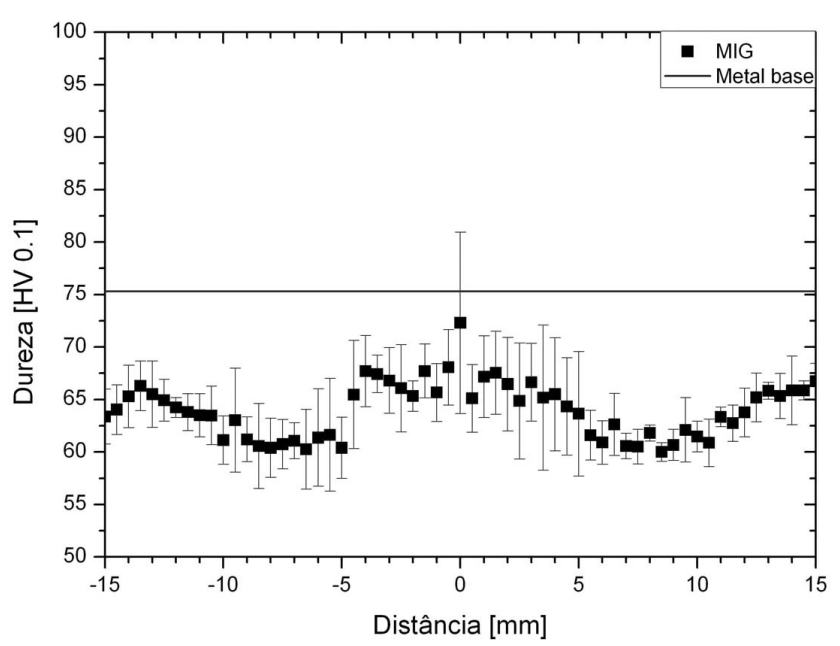

Figura 26. Perfil de microdureza médio - processo MIG.

Para a ferramenta com geometria cônica lisa (Figura 23) o desvio-padrão médio verificado é de $5,7 \mathrm{HV}$, e uma queda de aproximadamente $10 \mathrm{HV}$ ocorre em relação ao metal base. Também nota-se que a uma distância de aproximadamente $15 \mathrm{~mm}$ da linha central de solda ocorre a recuperação da dureza original do metal base, indicando que a perda de dureza concentra-se em uma zona de aproximadamente $30 \mathrm{~mm}$ no entorno da linha central da solda.

A Figura 24 mostra os valores médios de microdureza obtidos na avaliação das seções transversais obtidas com a geometria facetada. O desvio-padrão médio é de $6,7 \mathrm{HV}$, e a dureza média na região central é de cerca $65 \mathrm{HV}$. O retorno aos valores da dureza original do metal base ocorre na região situada a $15 \mathrm{~mm}$ da linha central de solda.

A geometria cônica com rosca tem seu perfil de dureza apresentado no gráfico da Figura 25. Novamente a queda máxima de dureza verificada é de aproximadamente $10 \mathrm{HV}$. Isto indica que a soldagem pelo processo FSW utilizando qualquer uma das três geometrias ocasiona um ciclo térmico muito semelhante, traduzindo-se em perfis de dureza similares. Neste caso, a recuperação da dureza original também se repete, ocorrendo próximo aos $15 \mathrm{~mm}$ de distância da linha central de solda.

Na Figura 26 observa-se o perfil de durezas obtido nas amostras soldadas através do processo MIG. Verifica-se uma queda mais acentuada dos valores de microdureza quando comparados aos obtidos pelo processo FSW, evidenciando-se a perda de dureza na região situada entre, 5 e $10 \mathrm{~mm}$, onde se verificam os menores valores de dureza medidos $(60 \mathrm{HV})$. A recuperação da dureza original do metal base não ocorre dentro da região de análise $(30 \mathrm{~mm})$, indicando que a ZAC resultante é mais extensa do que aquela decorrente do processo FSW. A menor redução de dureza na região do metal de solda pode ser atribuída à diluição.

\section{Conclusões}

Com base na análise dos resultados obtidos as seguintes conclusões podem ser delineadas: 
a) A ferramenta de soldagem com pino de geometria cônica lisa não apresentou desempenho satisfatório, como demonstrado pelos resultados dos ensaios de dobramento e tração. Verificouse a presença de uma descontinuidade que se estende ao longo de todo o comprimento soldado, presente em todas as repetições realizadas. A obtenção de soldas isentas de descontinuidades utilizando esta geometria de ferramenta requer a realização de ensaios adicionais com parâmetros de soldagem diferentes daqueles utilizados neste trabalho.

b) A ferramenta de soldagem com pino de geometria facetada apresentou desempenho satisfatório, não sendo observada presença de qualquer tipo de descontinuidade superficial nos testes de dobramento. Não foram verificadas descontinuidades como a presença de um canal longitudinal, como observado para a geometria cônica lisa. Nos ensaios de tração os corpos de prova tiveram bom desempenho, residindo nos valores obtidos de alongamento a evidência de desempenho superior às amostras obtidas com emprego da geometria cônica lisa.

c) A ferramenta de soldagem com pino de geometria cônica com rosca apresentou desempenho semelhante ao obtido pela ferramenta de geometria facetada. A análise macrográfica mostra que não há presença evidente de descontinuidades, fato comprovado pelo bom desempenho dos corpos de prova nos ensaios de dobramento transversal de face e de raiz, bem como nos ensaios de tração.

d) Em relação aos parâmetros de soldagem utilizados, podese afirmar que o desempenho obtido com velocidade de rotação de 1000 RPM, $3^{\circ}$ de inclinação da ferramenta, penetração do ombro de $0,4 \mathrm{~mm}$ e $75 \mathrm{~mm} / \mathrm{min}$ de velocidade de avanço mostra-se adequado para a obtenção de soldas com qualidade apreciável, utilizando-se as geometrias facetada e cônica com rosca, na soldagem de alumínio AA 5052-H34 com 6,35 mm de espessura.

e) As soldas obtidas utilizando-se o processo MIG tiveram seu desempenho comprometido devido à presença de porosidade ao longo do cordão. Desta forma, fica comprometida a comparação do desempenho entre os processos FSW e MIG, uma vez que os resultados obtidos para o processo MIG não necessariamente refletem o quê as melhores condições de soldagem poderiam oferecer.

f) A falha dos corpos de prova obtidos através do processo FSW origina-se na interface entre o núcleo da solda e o metal base, sendo que a ruptura ocorre sobre o cordão de solda. Na soldagem pelo processo MIG, observou-se a ruptura ao lado do cordão de solda, coincidente com a região de menor dureza verificada através dos ensaios de microdureza Vickers.

g) As chapas soldadas pelo processo MIG, embora sujeitadas por suportes de fixação, apresentaram distorção residual, fato não observado nas soldas pelo processo FSW.

h) A extensão da região onde se verifica perda de dureza nas soldas obtidas pelo processo FSW é de aproximadamente $30 \mathrm{~mm}$, sendo menor do que aquela observada no processo MIG. A variação ao longo do perfil da solda não é acentuada, não ficando evidentes diferenças na dureza entre as diferentes zonas microestruturais resultantes do processo. Quanto à queda de dureza, observa-se que no processo MIG os menores valores verificam-se entre 5 e $10 \mathrm{~mm}$ de distância da linha central de solda e são aproximadamente $5 \mathrm{HV}$ menores que a menor dureza observada na soldagem pelo processo FSW.

i) Os resultados obtidos mostram que a soldagem por FSW é capaz de produzir juntas de excelente qualidade, mesmo em ligas de alumínio consideradas de boa soldabilidade por processos de soldagem ao arco elétrico como é o caso da liga AA5052-H34, desde que utilizada uma combinação adequada de parâmetros de soldagem e geometria de ferramenta.

\section{Agradecimentos}

Os autores agradecem aos laboratórios de usinagem, soldagem (LS\&TC) e metalurgia física (LAMEF) da UFRGS, onde as soldas/ensaios foram realizados, e à CAPES pela bolsa de mestrado, que possibilitaram a execução deste trabalho.

\section{Referências Bibliográficas}

[1] ABAL. Centro de Informações Automotivo e de Transportes. ALUAUTO. n.10, 2006. Disponível em: <http://www.abal.org. br>. Acesso em: 27 out. 2006.

[2] THOMAS, W. M. et al. Friction stir butt welding. International Patent no. 9125978.8. Dez. 1991. Disponível em: <http://www. patent.gov.uk/>. Acesso em: 10 abr. 2006.

[3] THOMAS, W. M. et al. Friction stir welding tool and method. UK Publication Number GB 2306366. Out. 1996. Disponível em: <http://www.patent.gov.uk/>. Acesso em: 10 abr. 2006.

[4] COLLIGAN, K. Material flow behavior during friction stir welding of Aluminum. Welding Journal: Welding Research Supplement, vol. 78, nº 7, 1999, p. 229s - 237s.

[5] CEDERQVIST, L.; REYNOLDS, A. P.. Factors Affecting the Properties of Friction Stir Welded Aluminum Lap Joints. Welding Journal: Welding Research Supplement, vol. 80, nº12, 2001, p. $281 \mathrm{~s}-287 \mathrm{~s}$.

[6] GUERRA, M. et al. Flow patterns during friction stir welding. Materials Characterization, 49 (2003) 95-101.

[7] ZHAO, Y.; LIN, S.; QU, F.. The influence of pin geometry on bonding and mechanical properties in friction stir weld $2014 \mathrm{Al}$ alloy. Materials Letters, 59 (2005) 2948-2952.

[8] CAPELARI, Tiago V.. Friction Stir Welding de placas de alumínio 5652. In: Trabalhos de conclusão do curso de Engenharia Mecânica - 2002. Porto Alegre / RS : Escola de Engenharia da UFRGS/Biblioteca, 2003.

[9] GEREMIA, Wagner. Estudo preliminar sobre a influência da geometria das ferramentas e parâmetros de operação no processo de soldagem por friction stir welding em alumínio 5052. In: Trabalhos de conclusão do curso de Engenharia Mecânica - 2003/1. Porto Alegre / RS : Escola de Engenharia da UFRGS/Biblioteca, 2003.

[10] ASTM E 190. Standard Test Method for Guided Bend Test for Ductility of Welds. American Society for Testing and Materials, 1997.

[11] ASTM E 8M. Standard Test Methods for Tension Testing of Metallic Materials. American Society for Testing and Materials, 2000. [12] LARSSON, H.; KARLSSON, L.; SVENSSON, L.. Friction Stir Welding of AA 5083 and AA6082 aluminium. Svetsaren, n², p. $6-10,2000$. 